\title{
1989 E-MRS Spring Meeting Attracts Growing Audience
}

The 1989 Spring Meeting of the European Materials Research Society (E-MRS) was once again held within the Council of Europe in Strasbourg, France. The conference, May 30 through June 2, 1989, consisted of five symposia: Symposium A: International Symposium on Silicon MBE; Symposium B: Science and Technology of Defects in Silicon; Symposium C: Acoustical, Optical, and Thermal Wave Characterization of Materials; Symposium D: Beam Processing and Laser Chemistry; and Symposium E: Biomaterials. All symposia were well attended, demonstrating broad interest in materials research. Each session was organized independently, although technical synergies stimulated several participants to multiplex among various sessions.

In the late afternoons and evenings, cooperative weather allowed attendees to walk among the restaurants, shops, and charm of Strasbourg. A conference dinner and wine tasting of the vins d'Alsace was enjoyed by all at the nearby Klipfel Winery. A glitch in transportation arrangements even allowed a few participants to enjoy the winery in the morning hours!

The conference was formally opened by J.P. Massue (Higher Education and Research - Council of Europe) and L. Bellemin (Commission of the European Communities, Brussels). The Plenary Session featured four presentations. Prof. Jacques Friedel of the UniversiteParis-Sud, 1988 Von Hippel Award recipient, spoke on "Bonding in Clusters and Condensed Matter: The Role of Electron Correlation." He stressed that materials problems such as the properties of dislocation cores, point defects, and interfaces depend on electron correlation. Nobel Prize Laureate Prof. Klaus von Klitzing of the Max-Planck Institute then discussed "Quantum Phenom- ena in Semiconductors." Quantum devices such as the Two-Dimensional Electron Gas Field Effect Transistor (TEGFET) and quantum well lasers were emphasized.

In the third presentation, Prof. Bellemin reviewed the SCIENCE plan, which funds scientific research within EEC countries. Finally, Prof. G. Metakides of the Commission of the European Communities in Brussels discussed the ESPRIT program. Research in microelectronics, computer science, artificial intelligence, and cognitive science is funded by ESPRIT, also within the EEC countries.

The following summaries describe some of the highlights from this meeting. The proceedings were published by Elsevier Science Publishing.

G.E. Carver

AT\&T Bell Laboratories, U.S.A. and I.W. Boyd

University College London, U.K.

\section{Symposium A: International Symposium on Silicon MBE}

The third international silicon MBE conference was held during the 1989 E-MRS Spring Meeting. Its predecessors were held October 1987 in Honolulu, Hawaii, U.S.A., and May 1985 in Toronto, Canada. The third symposium was chaired by Dr. E. Kasper (AEG, West Germany) and Prof. E.H.C. Parker (University of Warwick, U.K.) with co-chairs Dr. J.C. Bean (AT\&T Bell Laboratories, U.S.A.), Dr. J.M. Phillips (AT\&T Bell Laboratories, U.S.A.), Prof. Y. Shiraki (Hitachi, Japan) and Prof. K.L. Wang (UCLA, U.S.A.)

The meeting was divided into 9 oral sessions featuring 48 contributed papers and 12 invited papers. Three sessions were devoted to GeSi growth and characterization, two sessions covered MBE Si growth and doping, and one session each was devoted to the following topics: alternating techniques for growth of epitaxial $\mathrm{Si}$ and $\mathrm{SiGe}$, devices fabricated with Si MBE, epitaxial silicide work, and growth of other epitaxial systems of interest to the Si MBE community. The two poster sessions included 46 papers, and an evening session was held on the future of Si MBE with two additional invited speakers.

The symposium was very well attended, indicating the continuing growth of the $\mathrm{Si}$

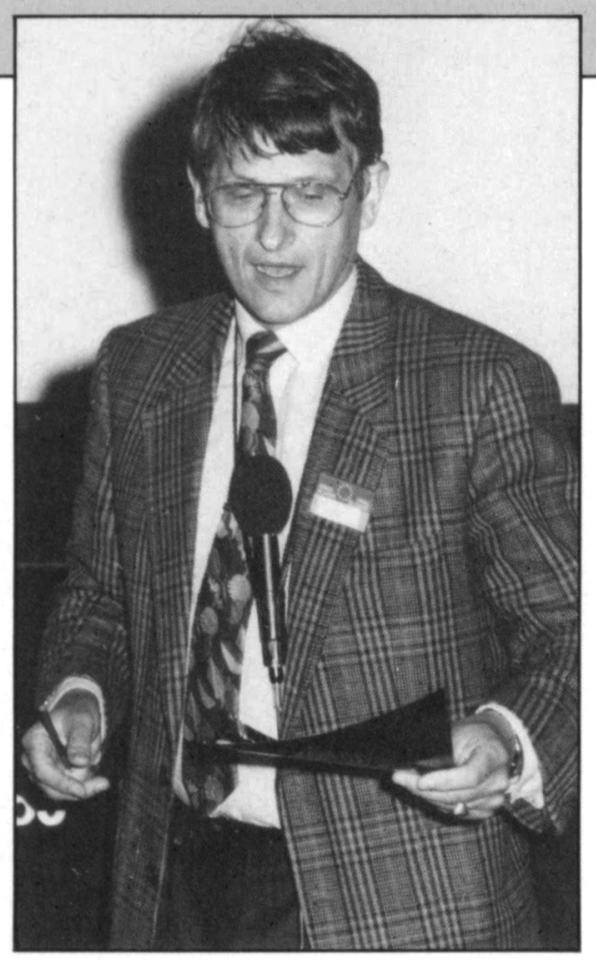

Plenary Speaker Klaus von Klitzing.

MBE community, particularly in Europe. As suggested by the number of SiGe sessions, this topic tended to dominate the symposium, with interest generated by applications for high-speed electronics (such as the heterojunction bipolar transistor) and optoelectronic applications. There continues to be substantial scientific interest in the possibility of creating direct band-gap semiconductors with $\mathrm{SiGe}$ superlattice structures, although no convincing evidence has yet been given which demonstrates that this is feasible. On the other hand, the heterojunction bipolar transistor has clear applications and competition now exists between $\mathrm{Si} M B E$ and vapor-phase epitaxial techniques for producing the required layers for this important device structure.

There were also many papers on heteroepitaxy of other materials on $\mathrm{Si}$, particularly heteroepitaxy of silicides. The papers were split between the oral presentations and the poster sessions. The epitaxial silicides are of interest for threedimensional device applications, ballisticelectron devices (such as the metal-base transistor), and infrared detectors.

The general consensus was that the meeting was valuable and that there should be a fourth international meeting in two years in the United States. At this time, however, a location has not been decided. Leo J. Schowalter

Rensselaer Polytechnic Institute, U.S.A. 


\section{Symposium D: Beam Processing and Laser Chemistry}

This latest symposium continued the series on beam-solid interactions that has been a major annual theme for E-MRS meetings. This year the symposium focused on ion-solid, laser-gas, laser-solid interactions and modifications applied to materials processing. Over 90 experimental and theoretical papers were presented (12 from specially invited speakers), and an average of 120 attendees attended the talks. In the field of ion processing, considerable interest was devoted to the use of ionized cluster beam for the growth of epitaxial metal films and of insulating layers on silicon. The other aspect of ion-assisted growth of deposited thin layers was also discussed.

New results and a better understanding of the amorphous to single-crystal transition of the influence of impurities, and of the growth of deposited amorphous layer induced by ion beams resulted from the symposium. The polycrystalline formation in ion-irradiated CVD Si layers was also reported, and the results were coupled nicely to the phenomenology of nucleation and explosive crystallization in laserirradiated amorphous layers.

Amorphization mechanisms were detailed in metal layers and in polymers. The use of high energy implants was reported for buried SOS and single-crystal silicide layers. In addition, basic studies on damage formation and annealing were also reported. The transition between ion and laser chemistry was underscored by interesting chemical effects during low energy ion-beam-assisted etching on one side and the formation of $\mathrm{Ge}_{x} \mathrm{Si}_{1-x} / \mathrm{Si}$ heterostructures by ion implantation and laser irradiation on the other.

The laser processing papers reflected the now almost exclusive use of the excimer range of lasers for low temperature film growth and etching. However, there were notable exceptions, and incoherent lamp engineering attracted much interest. In addition to the laser deposition and etching sessions, the renewed interest in laser ablation was reflected in the fact that a complete afternoon was devoted to this topic, covering ablation of polyimides and oxides to metal and superconducting films.

The poster session was very well attended and attracted 33 papers. The session lasted an afternoon, giving a welcome amount of time for discussion. Industrial applications through direct writing of metal structures were debated through a series of papers which kept strong interest up to the early hours of Friday evening.

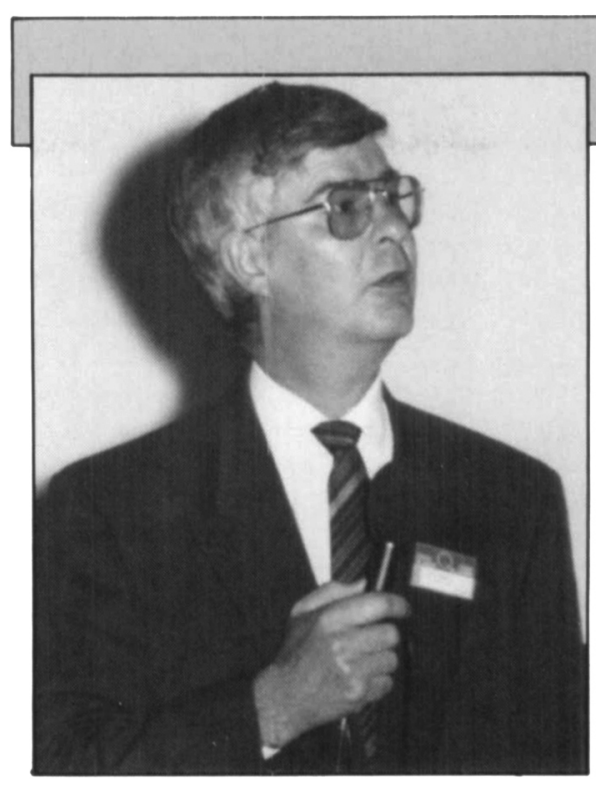

The Plenary Session is opened by

L. Belleinin (CEC).

Two awards were presented at the meeting to graduate students for their presentations in Symposium D. The awards were given in recognition of outstanding research in the field of beam processing. Students were judged on originality, quality and impact of their work. The recipients were Corrado Spinella, Department of Physics, University of Catania, Italy, whose paper was entitled "Amorphous to Polycrystal Transition in Ion Irradiated Chemical Vapour Deposited Amorphous $\mathrm{Si}^{\prime \prime}$; and A. Yahashi, from the Ion Beam Engineering Experimental Laboratory, Kyoto University, Japan, who addressed "The Structure Zone Model Applied to Ionized Cluster Beam Films: $\mathrm{Al}$ on $\mathrm{SiO}_{2}$."

I.W. Boyd

University College London, U.K.

E. Rimini University of Catania, Italy

\section{Symposium E: Biomaterials}

This was the first time that the E-MRS Meeting included a symposium on biomaterials. The theme, "Interfaces in Biomaterials Sciences," included sessions on surface characterization and treatment, interactions and their control, clinical aspects, and socio-economical and legal aspects. Each session commenced with a lecture by an invited speaker. Invited speakers were M. Davies (Nottingham, U.K.), who discussed static secondary ion mass spectrometry for the surface chemical analysis of biomaterials; P. Christel and M. Therin (Paris, France), who spoke about

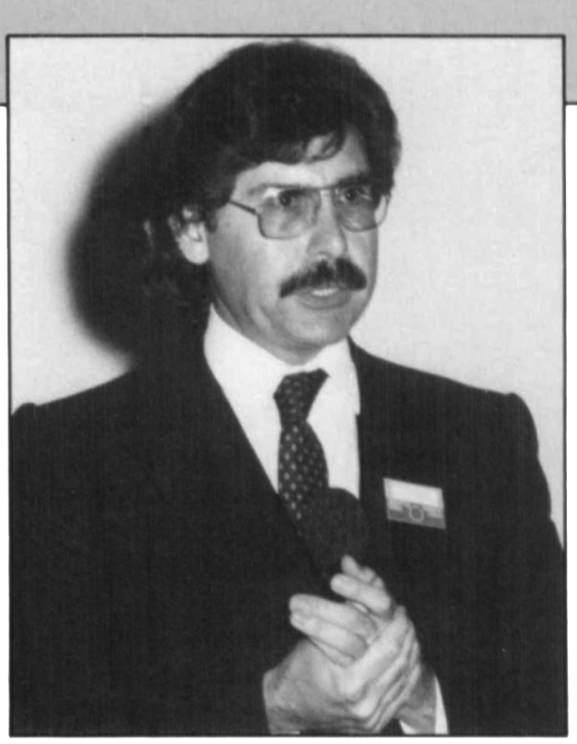

The Plenary Session is closed by

G. Metakides (CEC).

the quantification of the muscular tissue reaction to implanted biomaterials; and $\mathrm{H}$. Oonishi (Osaka, Japan), who addressed mechanical and chemical bonding of the artificial joints.

Because of its very specific nature, the last session provided three invited papers: S. Perren (Davos, Switzerland) on standardization of materials and implants by the ISO (International Standards Organization); K. Mattox (St. Paul, MN, U.S.A.) on where the opportunities are, from the marketing perspective; and J.M. Price (Minneapolis, MN, U.S.A.) on liabilities problems.

An average of 60 people attended the sessions, which were marked by a high degree of interest and discussion.

The importance of method for highresolution characterization was highlighted. The crucial problem of interactions was illustrated by a variety of methods which included implantation, all culture, microstructural examination. The clinical section dealt with joint replacement; maxillo-facial, nerve and ligament repair; and dental implants.

The poster session was also of high standard with 22 presentations which attracted large attendance. Communications or posters came from the following countries: U.K. (4), France (15), Switzerland (3), Italy (6), West Germany (7), Sweden (1), Poland (2), U.S.A. (4), and Japan (1).

D. Muster

L.E.E.D. Biomateriaux, France G. Hastings Medical Institute, Hartshill, U.K. 